Article

\title{
Academic Research, Higher Education, and Peripheral Development: The Case of Israel
}

\author{
Gad Degani ${ }^{1,2}$, Dan Levanon ${ }^{2}$ and Gregory Yom Din ${ }^{1, *(D)}$ \\ 1 Tel-Hai College, Upper Galilee 1220800, Israel; gad@migal.org.il \\ 2 MIGAL—Galilee Research Institute, POB 831, Kiryat Shmona 1101602, Israel; Danl@migal.org.il \\ * Correspondence: gregoryyd@gmail.com
}

check for updates

Citation: Degani, Gad, Dan Levanon, and Gregory Yom Din. 2021. Academic Research, Higher Education, and Peripheral Development: The Case of Israel. Economies 9: 121. https://doi.org/ 10.3390/economies 9030121

Academic Editor: Michele Meoli

Received: 24 July 2021

Accepted: 18 August 2021

Published: 27 August 2021

Publisher's Note: MDPI stays neutral with regard to jurisdictional claims in published maps and institutional affiliations.

Copyright: (c) 2021 by the authors. Licensee MDPI, Basel, Switzerland. This article is an open access article distributed under the terms and conditions of the Creative Commons Attribution (CC BY) license (https:/ / creativecommons.org/licenses/by/ $4.0 /)$.

\begin{abstract}
The aims of this study are to identify possible socioeconomic impacts of MIGAL (Galilee Research Institute) and TH (Tel Hai Academic College) on the peripheral northeast's development. We discuss the effects of academic research and institutions of higher education on mitigating differences between the center and the periphery of the country. MIGAL is a regional R\&D center in the northeast peripheral region of Israel. An internationally recognized applied research institute, MIGAL specializes in biotechnology, computational sciences, plant sciences, precision agriculture, and environmental sciences, as well as food, nutrition, and health. Most of MIGAL's researchers serve as the core faculty at TH. Despite the country's small surface area, socioeconomic inequality in Israel is high by OECD standards, with wage differences between rich and poor regions reaching up to $400 \%$. In this article, a new type of dataset for the study of the socioeconomic impact of academic research and higher education on peripheral development is proposed-the regional socioeconomic indices (SEIs). Data for MIGAL, TH, and the northeastern peripheral region were collected from the yearly reports of the two institutions and the Israel Central Bureau of Statistics. MIGAL was found to serve as a link between research, academic teaching, and socioeconomic development in the northeast periphery. Several variables related to this link and describing MIGAL-TH and northeastern periphery development were analyzed over time: MIGAL's budget, total number of employees and number of employees with PhDs; number of TH graduate students; and the socioeconomic index (SEI) of the northeastern periphery and its position on the Israeli list of regional SEIs. The signs and significance levels of most of the trends indicate a potential socioeconomic impact of academic research and higher education on peripheral development in the northeast of the country. Research budgets and the creation of jobs for academics living in the region are just a few examples of this impact. The results of the study are useful for academics and policymakers in improvement of the contribution of academic research and higher education to the country's economic and innovation development.
\end{abstract}

Keywords: regional development; periphery; socioeconomic index; academy; university

\section{Introduction}

MIGAL (Galilee Research Institute Ltd., Kiryat Shmona, Israel, established in 1979) is a regional $R \& D$ center of the Israeli Ministry of Science and Technology owned by the Galilee Development Company Ltd. An internationally recognized and multidisciplinary applied research institute, MIGAL specializes in biotechnology, computational sciences, plant sciences, precision agriculture, and environmental sciences, as well as food, nutrition, and health. MIGAL employees include more than $90 \mathrm{PhDs}$ and 190 researchers deployed across 44 research groups and operating as an innovative research ecosystem that encourages collaboration across scientific, industrial, agricultural, academic, and technological specializations (Levanon 2020) (Figure 1).

Most of MIGAL's researchers serve as the core academic and administrative staff of the Faculty of Sciences and Technology at Tel Hai Academic College (TH). Many of TH's graduate students are supervised by MIGAL scientists and conduct their research in 
MIGAL's laboratories. Since 1994, TH has been an independent academic institution that offers Bachelor and graduate degrees in the faculties of Social Sciences and Humanities and Science and Technology. TH pioneered the integration of practical, hands-on experience into college studies, providing students with valuable skills and knowledge and invigorating the local economy with youthful energy and ideas that challenge thinking and serve to formulate innovative approaches to science, engineering, design, and analysis (Levanon 2020; Tel-Hai College 2021) (Figure 1).

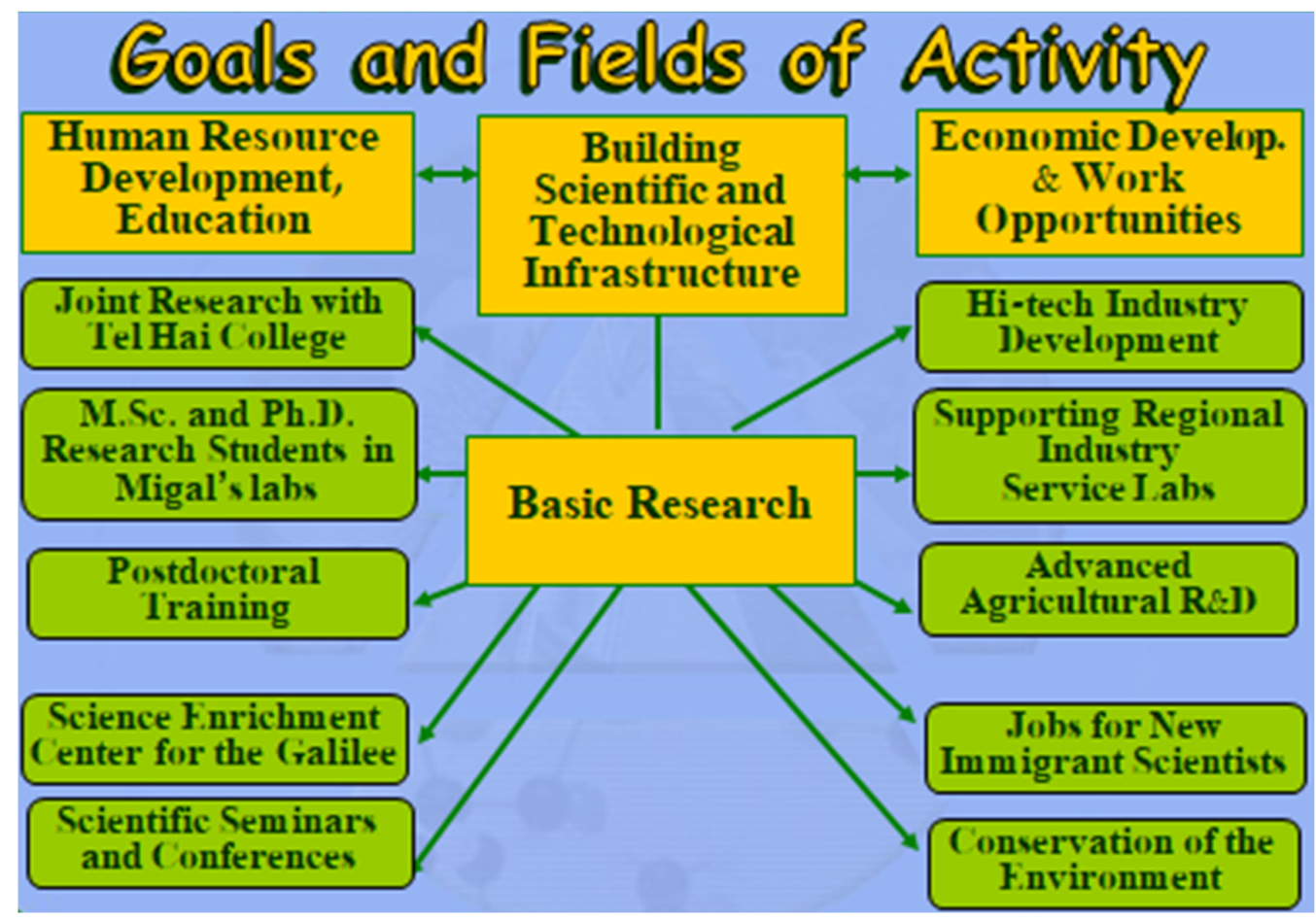

Figure 1. MIGAL's goals upon its establishment in 1979.

In this article, we discuss the possible impact of academic research and education institutions on mitigating differences between the center and periphery of the country. We study the case of MIGAL and TH, located in a peripheral region in northeastern Israel, and the channels of potential influence of MIGAL-TH on regional development. We explore this potential impact quantitatively using data on regional development in Israel from the establishment of MIGAL and TH until today.

Currently, most low-productivity sectors with low-quality and low-wage jobs are located in the peripheral regions of Israel. Despite the Encouragement of Capital Investments Law, the country's small surface area, and the availability of investment grants for the periphery, socioeconomic inequality in Israel is high by OECD standards.

The difference in monthly wage between the rich and poor regions can reach up to 400\% (Machlica 2020). The center of the northeastern Galilee region of Israel, the focus of this article, is the town of Kiryat Shmona. MIGAL and TH are located near this peripheral town, where, historically, education and employment opportunities have been low, similar to other "development" towns established to support the absorption of new immigrants (Tel Hai Innovation Center Team 2020).

The problem of developing peripheral regions through university-industry-government relations has been studied widely in the published research. In many studies, it is accepted that multinational enterprises, small firms, and households develop within their own ecosystem, similar to natural processes and in particular on geographic principles. The term "cross-industry ecosystem" is relevant in view of the interdisciplinary nature of modern innovations and knowledge in light of inter-sectoral collaboration (Tolstykh et al. 2021). 
The question is even more pertinent today, in a modern social environment characterized by the processes of innovation and migration. In the present empirical research, the significant features of this approach are analyzed. The aims of this study are to identify the ways in which MIGAL-TH might have a socioeconomic impact on the peripheral northeast's development, and to estimate this impact statistically.

We suggest the use of a new type of dataset for this purpose; specifically, we examine the socioeconomic indices (SEIs) of the northeastern region relative to other peripheral regions of Israel. We check the multiyear relationship between these indices and variables reflecting the development of MIGAL and TH-institutional budgets, staff, and number of graduate students. This research may serve to inform policy recommendations for knowledge-driven regional development aimed at equalizing socioeconomic conditions in the center and periphery of developed countries.

\section{Background and Literature Survey}

The medieval universities were sources of basic knowledge, separated from the rest of society. In the nineteenth century, the universities began to play a more active role, particularly through experimentation and more applied research. The first technological university in Israel, the Technion, was established in 1924 in Haifa. Its first departments were architecture, civil engineering, and energy, later supplemented with high-tech fields such as computer science, biotechnology, stem cell research, space research, and nanotechnology. After World War II, funding for universities' basic and applied research grew substantially the world over, contributed by governments and commercial firms. In the United States, for example, university R\&D expenditures grew higher than the economy as a whole. With time, universities evolved from providing conventional research and teaching activities to being a knowledge hub that promotes innovation (Youtie and Shapira 2008).

Today, besides providing traditional education and performing research, academic education and research institutions (hereafter academic institutions) perform other functions that are important for regional development. For instance, they provide knowledge-intensive services and technical expertise for business R\&D activities (Grossman et al. 2001) and operate as global pipelines for international academic research networks (Bathelt et al. 2004).

In the historical context, researchers suggest an evolution in the role of universities from a knowledge storehouse to a knowledge factory, and on to a knowledge hub. Youtie and Shapira (2008) examined this process using the case of the Georgia Institute of Technology (USA). The state efforts to shift the region from an agricultural to an industrial and then to an innovation-driven economy were analyzed in the context of academic education and research roles.

Their role extends beyond the mere transfer of technology at the regional level and can, in fact, attract talent from other areas to the region. There is growing evidence that excellent universities, together with a regional innovation system that promotes inter-firm collaboration and business-university interactions, can boost regional competitiveness (Garcia-Alvarez-Coque et al. 2021). Published research examining the relationship between academic institutions and regional competitiveness has shown a strong relationship between research achievements and regional industrial development. In peripheral regions, one of the functions of universities is to cover deficits in the R\&D infrastructure (GarciaAlvarez-Coque et al. 2021). The effectiveness of academic research and higher education from a regional standpoint and universities' influence on regional development have been assessed using various analytical models. One such model, the Triple Helix model of University-Industry-Government relations, describes the enhanced role of the university in processes of innovation in knowledge-based societies. This model is used in one form or another in government and academic initiatives for knowledge-based economic development in the United States, European countries, and many others. It states that the university (and in our case, research institute and academic college) can play an enhanced role for the purpose of innovation in increasingly knowledge-based societies, specifically in the social context (Etzkowitz and Leydesdorff 2000). 
In another-Quadruple Helix-model, researchers assume that society also plays an important role in the innovation process, along with science, business, and the state, and impacts the creation of knowledge and technology at different levels of institutional, regional, and operational functionality. Research from Russia for the period of 2008-2014 confirmed the indirect impact (through the development of a "knowledge space") of academic education on the level of socioeconomic development and on the relationship between the index of scientific-technological potential of the region and the size of the gross regional product per capita (Kurbatova and Kagan 2017).

In a study from Spain covering the period 2003-2015, a moderately positive relationship was found between the level of university-firm collaboration (UFC) and most regional development indicators in that country. UFC was shown to strengthen industrial knowledge management and innovation capacity, indirectly having a positive effect on the regional economy and human capital. UFC can also generate positive effects on social life and serve a base of regional entrepreneurships in the context of the Triple Helix Model (Manrique 2019).

Significant features of these models are used in the current research to examine a case study of the Upper Galilee region of Israel, one of the peripheral regions in the north of the country. We employ the "research-academic education-regional development" model in our research based on the socioeconomic index (SEI) used in Israel. SEI reflects the socio-economic status of the population in the region-education, employment, income level, and other characteristics. This MIGAL-TH model is implemented for the Upper Galilee region with a focus on academic and industrial aspects of biotechnology.

\section{Methodology}

\subsection{Data}

Data on MIGAL and TH were collected by the authors from these institutions' yearly reports. Table 1 shows an excerpt of these data for MIGAL, and Table 2 for TH.

Table 1. An excerpt of the MIGAL data used in this study.

\begin{tabular}{ccccc}
\hline Item & $\mathbf{2 0 1 1}$ & $\mathbf{2 0 1 2}$ & $\mathbf{2 0 1 3}$ & $\mathbf{2 0 1 4}$ \\
\hline budget, mln. NIS & 47.7 & 54.1 & 61.3 & 57.6 \\
workers & 180 & 180 & 180 & 220 \\
PhD workers & 42 & 44 & 53 & 60 \\
\hline
\end{tabular}

Table 2. An excerpt of the TH data used in this study.

\begin{tabular}{ccccc}
\hline Item & $\mathbf{2 0 1 7}$ & $\mathbf{2 0 1 8}$ & $\mathbf{2 0 1 9}$ & $\mathbf{2 0 2 0}$ \\
\hline MA students & 28 & 28 & 54 & 55 \\
PhD students & 6 & 6 & 7 & 6 \\
\hline
\end{tabular}

The SEI data on the northeastern region for the researched period were collected from the Israel Central Bureau of Statistics (Table 3).

Table 3. An excerpt of the SEI data for the northeastern peripheral region used in this study.

\begin{tabular}{ccccc}
\hline Item & $\mathbf{2 0 0 6}$ & $\mathbf{2 0 0 8}$ & $\mathbf{2 0 1 3}$ & $\mathbf{2 0 1 5}$ \\
\hline SEI & 0.241 & 0.225 & 0.423 & 0.550 \\
position on list of regional SEIs for Israel & 31 & 36 & 26 & 13 \\
\hline
\end{tabular}

Data were not always available for all years of the researched period. Nevertheless, we were able to examine possible increasing trends in MIGAL's budget and number of researchers, as well as in TH's number of students. The SEI data (Table 3) were related to the values over time for the northeastern periphery (a possible positive trend was examined), 
and to the position of this region on the Israeli list of regional SEIs (a possible rising trend of moving up toward the top of this list was examined).

\subsection{Model}

To examine possible trends in the data described in the previous subsection, we used ordinary least squares (OLS) regression:

$$
y_{k t}=\alpha_{k}+\beta_{k} t
$$

where $t$ is the year of the researched period 1996-2020; $k$ is a number indicating the variable being examined: (1) MIGAL's budget, (2) workers, and (3) PhD workers, (4) TH's graduate students, and the northeast region's (5) SEI and (6) position on the Israeli list of regional SEIs, for a total of six time series ( $k=1$ to 6$) ; y_{k t}$ is the value of time series $k$ in year $t$; and $\alpha_{k}, \beta_{k}$ are the sought-after coefficients of the model for each time series $k$.

Our hypothesis in this study was that the studied time trends of the examined variables are statistically significant at the $5 \%$ level.

\section{Results}

The Microsoft Excel Analysis ToolPak was used for model (1) estimation. The periods of available data for the six times series all differed slightly.

MIGAL's budget and number of employees have increased significantly over the years. MIGAL has proven to be an important institution that employs more than 200 academics in the region, many of whom (more than 80 ) are $\mathrm{PhD}$ researchers. MIGAL is a workplace where postgraduate students, $\mathrm{PhD}$ students, and postdoctoral fellows can carry out their research, and this enables them to live in the northeast, making up a strong population. It is also an important option for citizens living in the region to apply their knowledge and experience without having to go to the center of the country where most of the academic research institutions are located.

All three MIGAL time series-for budget, number of employees, and number of $\mathrm{PhD}$ employees—showed positive trends, and the $\mathrm{R}^{2}$ measures were relatively large: from 0.87 to 0.92 (Figures 2 and 3).

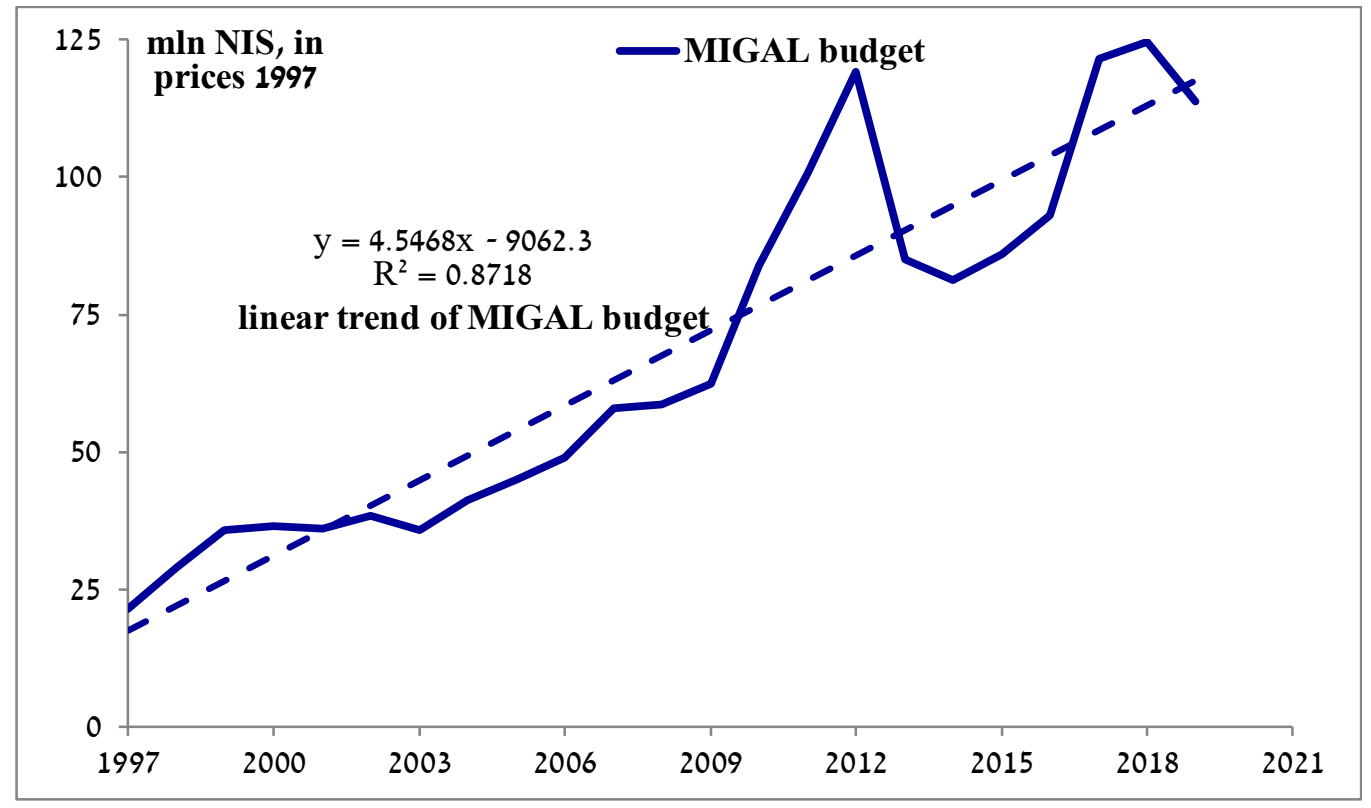

Figure 2. MIGAL budget, in prices, from 1997. 


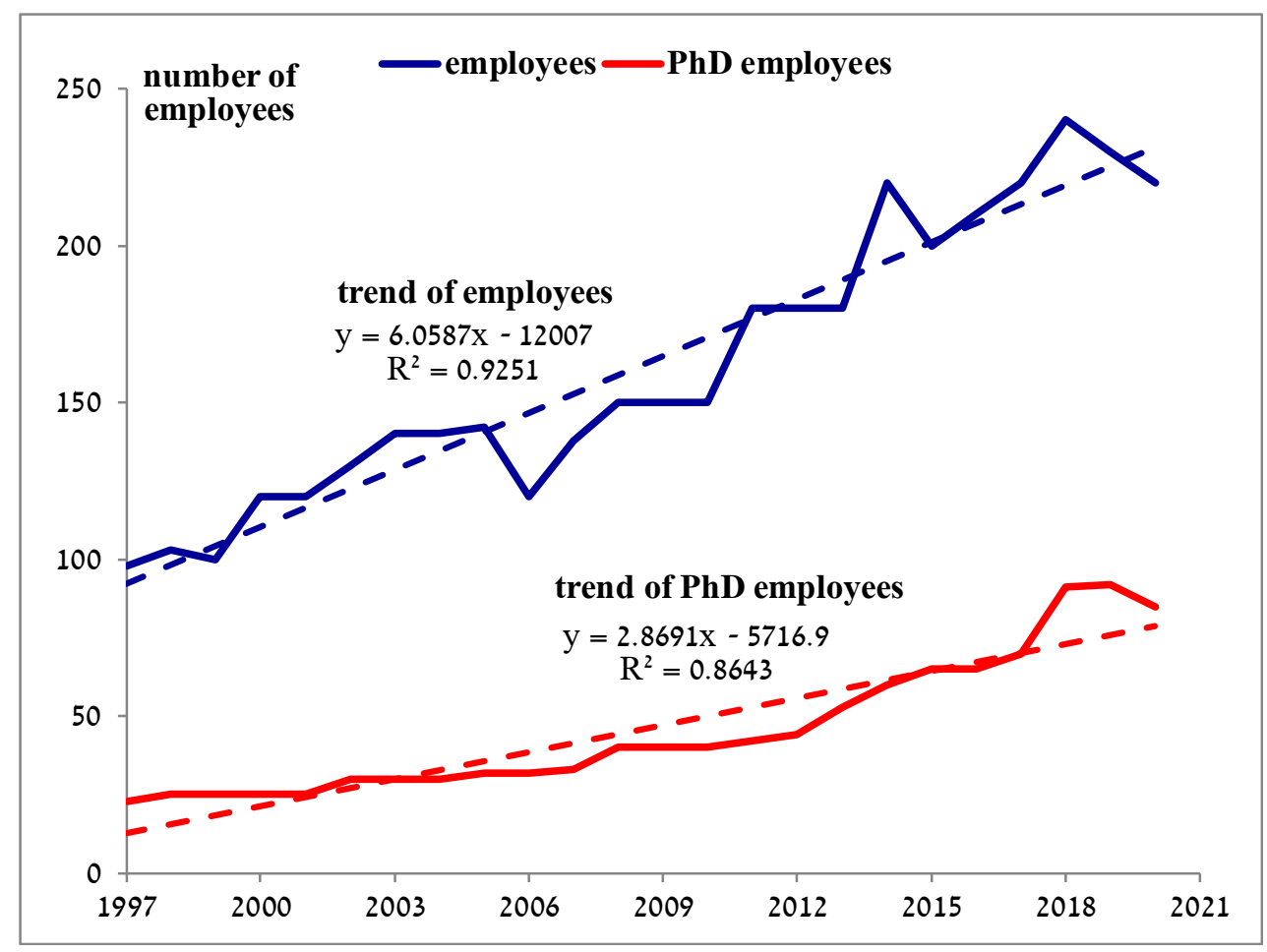

Figure 3. Number of MIGAL employees—-total and with PhD degree.

The number of undergraduate and graduate students has increased at TH. Some of this increase is due directly to MIGAL's influence, and some of it is related to the academic development of $\mathrm{TH}$, which operates like a university for certain disciplines. The time series for graduate students showed a positive trend, but the $\mathrm{R}^{2}$ measure was relatively small, 0.25 (Figure 4).

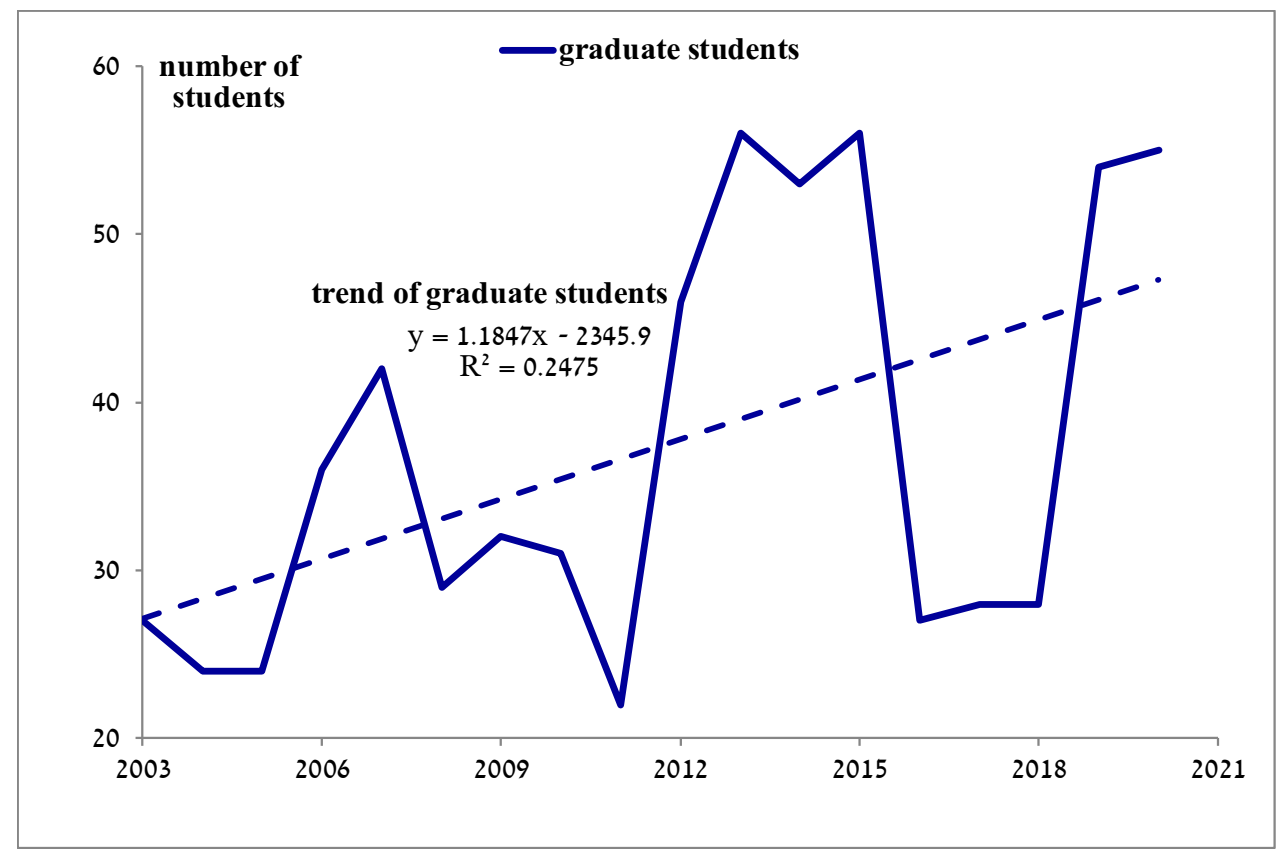

Figure 4. Number of graduate students at TH over time.

The SEI of the northeastern periphery increased during the research period (1999-2015) with an $\mathrm{R}^{2}=0.42$. The position of the region on the Israeli list of all regional SEIs rose, 
from 33rd in 1999 to 13 th in 2015, moving toward the top of the list with a relatively large $\mathrm{R}^{2}=0.59$ (Figure 5).

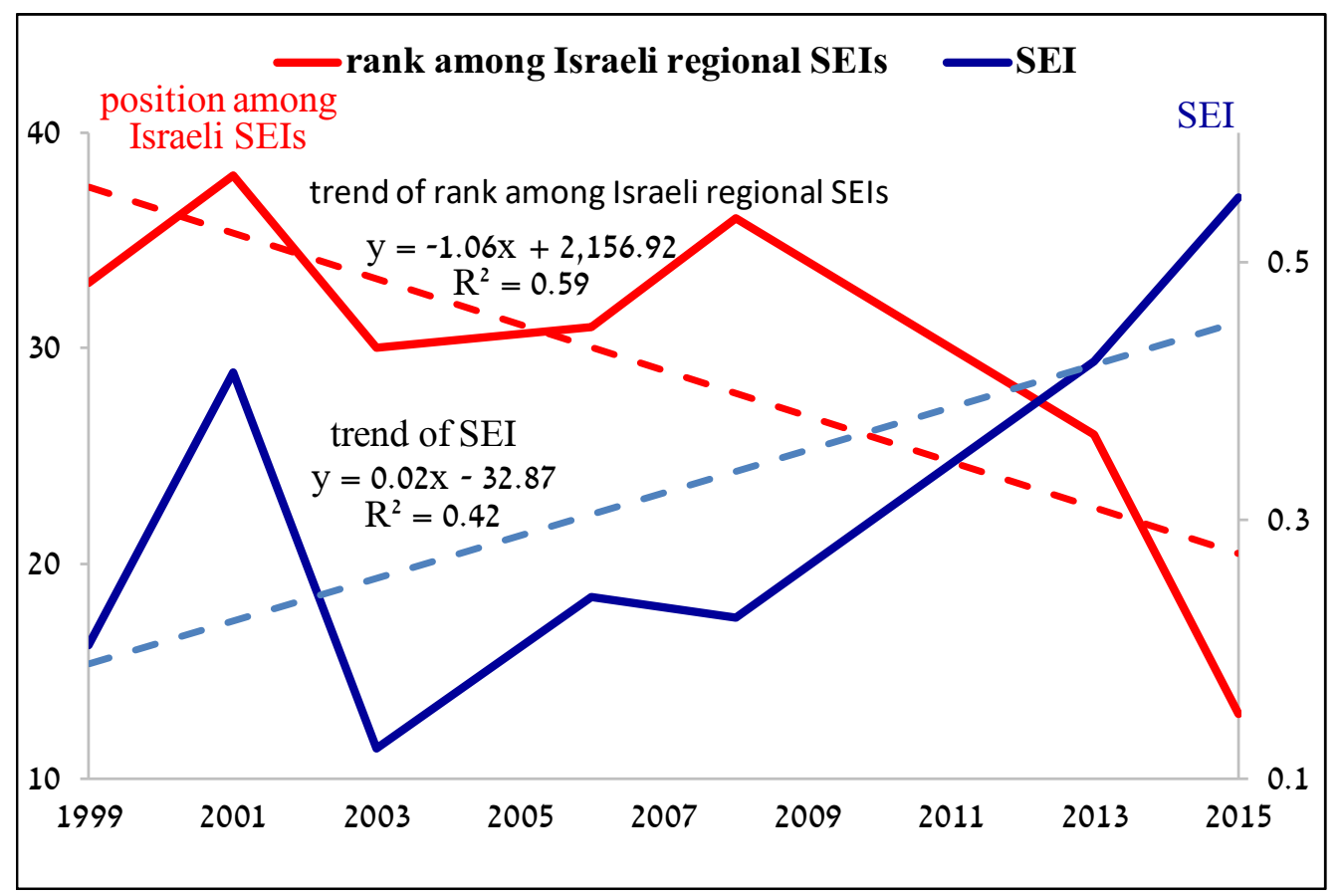

Figure 5. SEI of the northeastern periphery and position on the Israeli list of regional SEIs.

The model (1) was estimated for all six time series. The significance test results are summarized in Table 4 . The significance level was small $(p=0.00)$ for the time series related to the possible socioeconomic impact of academic research (MIGAL) and higher education $(\mathrm{TH})$, and relatively small $(p=0.08)$ for the time series related to development in the periphery (SEI).

Table 4. Significance of the time series trends and slopes in model (1).

\begin{tabular}{ccc}
\hline Time Series & Trend & $p$-Value from Model (1) \\
\hline MIGAL budget & rise & 0.00 \\
\hline MIGAL employees & rise & 0.00 \\
MIGAL PhD employees & rise & 0.00 \\
TH graduate students & rise & 0.04 \\
SEI of the northeast & rise & 0.15 \\
position of the northeast on & rise to the top of the list & 0.08 \\
the Israeli list of regional SEIs & & \\
\hline
\end{tabular}

\section{Discussion and Conclusions}

The academic institution MIGAL serves as a link between research, academic teaching, and socioeconomic development in the northeastern periphery of Israel. In this study, several time series related to this link and describing MIGAL-TH and northeast development were analyzed. For all of the studied time series, the signs and level of significance of the trends indicated the existence of a possible socioeconomic impact of academic research and higher education on peripheral development of the northeast region. Research budgets and creating jobs for academics living in the region are just one explanation for this possible impact. Our empirical findings are consistent with the paradigm of the Triple Helix model that describes the new role of academic institutions in innovation processes that are ongoing in knowledge-based societies. In this study, we used this paradigm in the context of regional development in the periphery of Israel. 
The empirical results of our study are in line with findings of other studies in this field. Garcia-Alvarez-Coque et al. (2021) analyzed data from Spain and concluded that R\&D expenditure and academic contribution are important for regional competitiveness. They found that university excellence is not crucial and needs to be contextualized in each specific case. In the study of Ierapetritis (2019), the role of the Greek Universities in developing the Innovation and Entrepreneurship Units was studied through the collection and processing of innovation information and actions.

Rodionov and Velichenkova (2020) studied 85 regions in the Russian Federation. They used a list of statistical socioeconomic indicators based on the regions' performance in previous years. This is similar to the regional SEI used in our study. Rodionov and Velichenkova (2020)'s findings highlight the importance of higher education institutions in the Russian regional innovation system, and of joint R\&D and the training of qualified personnel.

One of the limitations of our empirical research was use of the OLS regression, which assumes constant coefficients of the estimated trends of socioeconomic development. Another limitation was the length of the studied period, raising the need for longer and more consistent time series in future research in this area.

Future research in this field should include additional directions for regional academic and socioeconomic development. For the case of the Israeli northeast, for example, these might include the following relevant interactions related, in part, to the neighboring Galilee regions of Carmiel, Kinneret, and Golan: bio-environment services, including Kinneret research centers, educational institutions, including those for Ethiopian immigrants and the Arab sector, agricultural research and farmers' organizations, and industry-based development, in particular technology incubators and a biotech park (Figure 6).

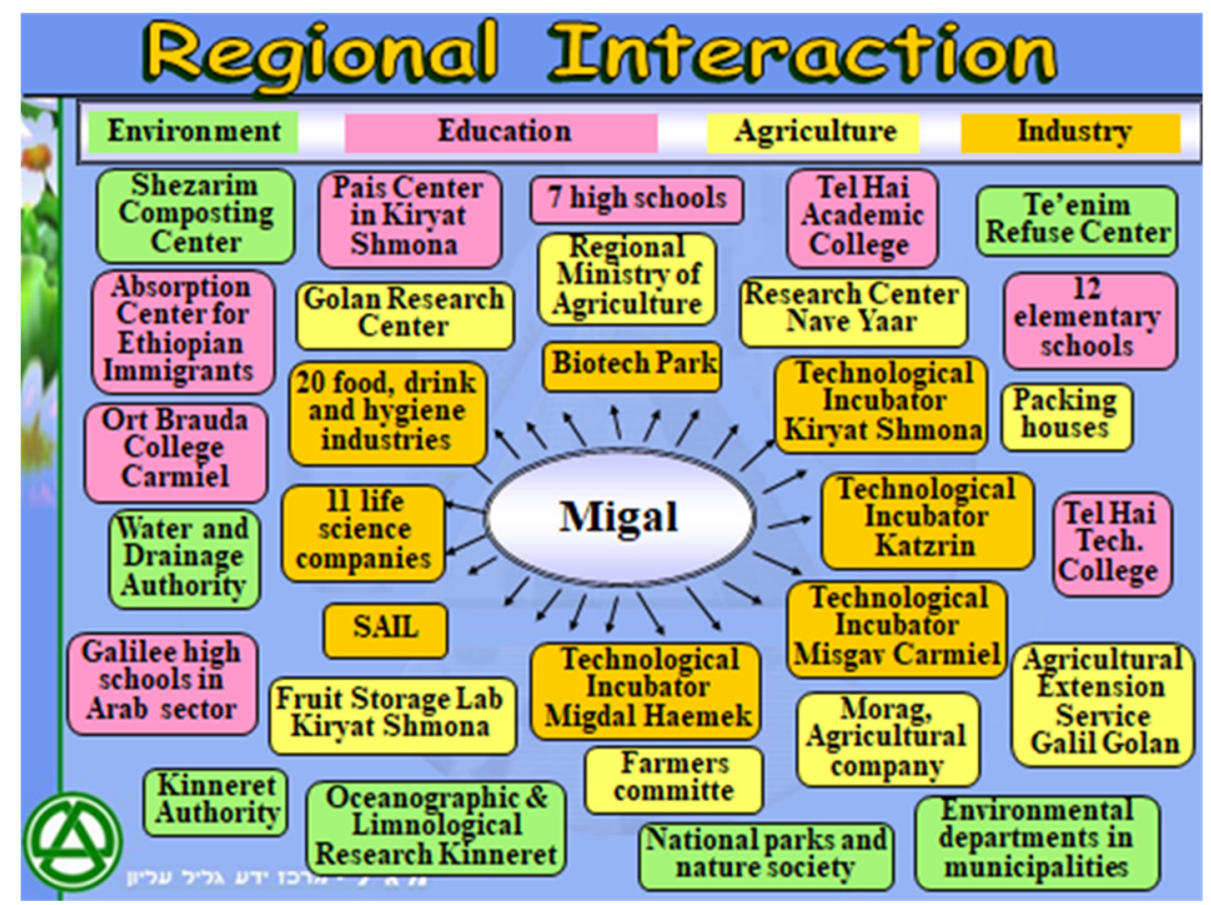

Figure 6. The direct and indirect effects of MIGAL on development of the northeast of Israel (Levanon 2020).

Author Contributions: All authors contributed equally to the work. All authors have read and agreed to the published version of the manuscript.

Funding: This research was funded by MIGAL, Galilee Research Institute, Israel.

Conflicts of Interest: The authors declare no conflict of interest. 


\section{References}

Bathelt, Harald, Anders Malmberg, and Peter Maskell. 2004. Clusters and knowledge: Local buzz, global pipelines and the process of knowledge creation. Progress in Human Geography 28: 31-56. [CrossRef]

Etzkowitz, Henry, and Loet Leydesdorff. 2000. The dynamics of innovation: From National Systems and "Mode 2" to a Triple Helix of university-industry-government relations. Research Policy 29: 109-23. [CrossRef]

Garcia-Alvarez-Coque, Jose-Maria, Francisco Mas-Verdú, and Norat Roig-Tierno. 2021. Life below excellence: Exploring the links between top-ranked universities and regional competitiveness. Studies in Higher Education 46: 369-84. [CrossRef]

Grossman, Jerome H., Proctor P. Reid, and Robert P. Morgan. 2001. Contributions of academic research to industrial performance in five industry sectors. The Journal of Technology Transfer 26: 143-52. [CrossRef]

Ierapetritis, Dimitrios G. 2019. Discussing the Role of Universities in Fostering Regional Entrepreneurial Ecosystems. Economies 7: 119. [CrossRef]

Kurbatova, M. V., and E. S. Kagan. 2017. The role of universities in the formation of scientific and technological potential and in development of Russian Federation regions. University Management: Practice and Analysis. [CrossRef]

Levanon, Dan. 2020. Establishment of MIGAL-Early Years 1979-85. unpublished.

Machlica, Gabriel. 2020. Reducing Socio-Economic Differences between Municipalities in Israel. OECD Economic Department Working Paper, No. 1645. Paris: OECD Publishing.

Manrique, Sergio. 2019. Exploring the Impact of University-Firm Collaboration on Regional Development: The Spanish Case. Available online: https:/ / runinproject.eu/results / working-paper-series (accessed on 16 August 2021).

Rodionov, Dmitrii, and Daria Velichenkova. 2020. Relation between Russian universities and regional innovation development. Journal of Open Innovation: Technology, Market, and Complexity 6: 118. [CrossRef]

Tel Hai Innovation Center Team. 2020. From entrepreneurship courses to a regional innovation and entrepreneurship center: A model for innovation and entrepreneurship center at Tel Hai Academic College. In SILICE-Best Practices for Innovation Centers in Higher Education Institutions. Tel Hai: Tel Hai Innovation Center Team, Chapter 4. pp. 33-49. Available online: https:/ / www.silice.org/wp-content/uploads/SILICE-SINOLABS-HANDBOOK.pdf (accessed on 16 August 2021).

Tel-Hai College. 2021. Available online: https:/ / english.telhai.ac.il/ (accessed on 16 August 2021).

Tolstykh, Tatyana, Leyla Gamidullaeva, and Nadezhda Shmeleva. 2021. Universities as Knowledge Integrators and Cross-Industry Ecosystems: Self-Organizational Perspective. SAGE Open 11: 2158244020988704. [CrossRef]

Youtie, Jan, and Philip Shapira. 2008. Building an innovation hub: A case study of the transformation of university roles in regional technological and economic development. Research Policy 37: 1188-204. [CrossRef] 